\title{
Covert video surveillance continues to provoke debate
}

\author{
Elliot A Shinebourne Royal Brompton Hospital, London
}

\begin{abstract}
When the editor invites comment on a response ${ }^{1}$ to an analysis $^{2}$ of a criticism $^{3}$ of a protocol ${ }^{4}$ already defended by the author in this journal, ${ }^{5}$ the issue is clearly contentious. I will comment briefly on Thomas's paper in this issue of the journal, and look at points of agreement as well as dissent.
\end{abstract}

Whether the infant or the parent is videoed is not simply a semantic difference. At the time covert video surveillance (CVS) was introduced, the Brompton Hospital Research Ethics Committee agreed that filming the whole cubicle could be construed as spying on the parents. That is why the baby alone was filmed.

That a protocol for CVS had been reviewed by a local research ethics committee has now been acknowledged by Thomas. I agree with him that surveillance is better carried out by police than nurses, but the police have also to agree.

The notion espoused by Thomas, that running a video camera is harmless much as a gun lying unused on a table is harmless, is stultifyingly absurd. The only harm the video camera can do to the child is if it were inadvertently dropped on it!

I agree with the statement that natural justice is premised on the belief that people are innocent until proved guilty. Videoing a child who may be subject to suffocation is undertaken to find out if this is what is happening. Guilt is determined not by the act of filming but by the acts of the perpetrator if recorded on film. The video camera records and makes no assumptions.

\section{Key words}

Covert video surveillance; child protection; Munchausen's syndrome by proxy.
When a child presents for assessment of an acute life-threatening event, the doctor responsible has a duty of care to the child to find the cause and if possible prevent recurrence. If a child is admitted to hospital and dies suddenly and unexpectedly, it is the medical staff who are first called upon to explain the cause and it is this circumstance that I addressed in my previous paper.

Finally Thomas states that he had argued elsewhere that CVS might properly be the subject of judicial oversight. This presumably implies acceptance of the technique, under some circumstances. $\mathrm{He}$ also states that leave of the court should be sought every time CVS is considered. If this can be achieved speedily enough to protect the child, I can but agree. A multidisciplinary group at present reviews the indications for CVS before implementation but if it is felt the court would be preferable so be it. Contrary to Thomas's assertion, however, to my knowledge no one has disagreed with this.

Elliot A Shinebourne, MD, FRCP, is Consultant Paediatric Cardiologist at the Royal Brompton Hospital, London.

\section{References}

1 Thomas T. Covert video surveillance: the Staffordshire Protocol - a response to Dr Shinebourne. Fournal of Medical Ethics 1996; 22: 349-350.

2 Shinebourne EA. Covert video surveillance and the principle of double effect: a response to criticism. Fournal of Medical Ethics 1996; 22: 26-8.

3 Thomas T. Covert video surveillance - an assessment of the Staffordshire Protocol. Fournal of Medical Ethics 1996; 22: 22-5.

4 Staffordshire Area Child Protection Committee. (ACPC). Guidelines for the multi-agency management of patients suspected or at risk of suffering from life threatening abuse resulting in cyanotic-apnoeic episodes. 1994 Jan.

5 Southall DP, Samuels MP. Some ethical issues surrounding covert video surveillance - a response. fournal of Medical Ethics 1995; 21: 104-5, 115. 